\title{
Risk of renal events following intravenous iodinated contrast material administration among inpatients admitted with cancer a retrospective hospital claims analysis
}

Chaan S. Ng${ }^{1}$, Sanjeeva P. Kalva ${ }^{2}$, Candace Gunnarsson ${ }^{3^{*}}$ (D, Michael P. Ryan ${ }^{3}$, Erin R. Baker ${ }^{3}$ and Ravindra L. Mehta ${ }^{4}$

\begin{abstract}
Background: There is little published evidence examining the use of contrast material (CM) and the risk of acute renal adverse events (AEs) in individuals with increasingly common risk factors including cancer and chronic kidney disease (CKD). The objective of this study was to use real world hospital data to test the hypothesis that inpatients with cancer having $\mathrm{CT}$ procedures with iodinated $\mathrm{CM}$ would have higher rates of acute renal AEs in comparison to inpatients without cancer.
\end{abstract}

Methods: Inpatient hospital visits in the Premier Hospital Database from January 1, 2010 through September 30, 2015 were eligible for inclusion. The outcome of interest was a composite of acute renal AEs including: acute kidney injury, acute renal failure requiring dialysis, contrast induced-acute kidney injury and renal failure. Multivariable models, adjusted for differences in patient demographics and comorbid conditions, were used to estimate the incremental risk of acute renal AEs by $C T$ (with or without iodinated CM), CKD stage and type of cancer.

Results: Among 29,850,475 inpatient visits across 611 hospitals, 7.4\% had record of a CT scan, 5.9\% had CKD, and 3.4\% had the primary diagnosis of cancer. The baseline risk for an acute renal AE in patients without cancer or CKD and no $\mathrm{CT}$ or $\mathrm{CM}$ was $0.5 \%$. The absolute risk increases from baseline by $0.2 \%$ with a $\mathrm{CT}$ and by $0.8 \%$ with iodinated CM. Patients with CKD having a CT scan with iodinated CM have an absolute risk of 4.1 to $9.7 \%$ depending on the stage of CKD. For patients with cancer, the absolute risk increases, varying from 0.3 to $2.3 \%$ depending on the type of cancer.

Conclusions: Inpatients with cancer are at higher likelihood of developing acute renal AEs following CT with iodinated CM compared to those without a cancer. Understanding the underlying risks of acute renal AEs among complex inpatient admissions is an important consideration in treatment choices for oncology patients.

Keywords: lodinated contrast media, Acute renal event, Cancer, Contrast-induced nephropathy, Contrast-induced acute kidney injury, Computed tomography

\footnotetext{
* Correspondence: cgunnarsson@ctifacts.com

${ }^{3}$ CTI Clinical Trial \& Consulting Services100 E, RiverCenter Blvd, Covington, KY 41011, USA

Full list of author information is available at the end of the article
}

(c) The Author(s). 2018 Open Access This article is distributed under the terms of the Creative Commons Attribution 4.0 International License (http://creativecommons.org/licenses/by/4.0/), which permits unrestricted use, distribution, and reproduction in any medium, provided you give appropriate credit to the original author(s) and the source, provide a link to the Creative Commons license, and indicate if changes were made. The Creative Commons Public Domain Dedication waiver (http://creativecommons.org/publicdomain/zero/1.0/) applies to the data made available in this article, unless otherwise stated. 


\section{Background}

Adverse events (AEs) following intravascular administration of iodinated contrast material (CM) occur in 0.02 to $0.04 \%$ of patients. These include kidney injury, respiratory or cardiac arrest, convulsions, and loss of consciousness [1-3]. Renal insufficiency has been noted as both contributing to the risk of a post-CM AEs and as a result thereof [4-6]. However, the incidence of nephropathy specifically caused by iodinated $\mathrm{CM}$ is not well understood. As noted by the American College of Radiology, most published studies focus on the diagnosis of post-contrast acute kidney injury (PC-AKI), which is defined as sudden deterioration in renal function within $48 \mathrm{~h}$ following the intravascular administration of iodinated CM. PC-AKI is a correlative diagnosis, a subset of PC-AKI cases are contrast-induced nephropathy (CIN or CI-AKI), which is a causative diagnosis [7]. CI-AKI is commonly defined as an increase in serum creatinine $(\mathrm{SCr})$ greater than $25 \%$ or $44.2 \mathrm{umol} / \mathrm{L}(0.5 \mathrm{mg} / \mathrm{dL})$ from baseline within 2 or 3 days of intravascular $\mathrm{CM}$ administration in the absence of an alternative cause $[5,8]$. CI-AKI has an estimated incidence of 8 to $20 \%$ of cancer patients who undergo contrast-enhanced CT [6, 9-11]. However, most studies do not include a control group for analysis, which is problematic due to the variation in $\mathrm{SCr}$ observed in hospitalized patients regardless of CM administration [5]. Depending on the definition utilized, AKI has been reported in 6 to $35 \%$ of inpatients without $\mathrm{CM}$ exposure $[5,12]$.

Cancer treatments as well as the timing of treatment and CT imaging have been investigated as risk factors for acute reactions to iodinated CM [13, 14]. Other than chronic kidney disease (CKD), risk factors for CI-AKI include diabetes, hypertension, malignancy, age $>65$ years, use of non-steroidal anti-inflammatory drugs, and timing of $\mathrm{CT}$ within 45 days after last chemotherapy [9, 15]. Regardless of the cause, cancer patients who develop renal failure may have worse prognosis and survival [16-19].

While the biomedical literature indicates that the rate of AEs associated CM use is low, there is little evidence examining the use of $\mathrm{CM}$ and the risk of renal AEs in individuals with increasingly common risk factors including cancer and CKD. The objective of this study was to use real world hospital data to test the hypothesis that patients with cancer having $\mathrm{CT}$ with iodinated $\mathrm{CM}$ would have higher rates of acute renal AEs than those without cancer.

\section{Methods}

\section{Data source}

Data for the study were derived from the Premier Hospital Database, which currently contains data from more than 350 million patient encounters, or one in every five discharges in the United States (US) [20]. The database contains data from standard hospital discharge files, including a patient's demographic and disease state, and information on billed services, including medications, laboratory, diagnostics and therapeutic services in de-identified patient daily service records. In addition, information on hospital characteristics, including geographic location, bed size and teaching status are also available. Preliminary comparisons between patient and hospital characteristics for the hospitals included in the database and those of the probability sample of hospitals and patients selected for the National Hospital Discharge Survey (NHDS) suggest that the patient populations are similar with regard to patient age, gender, length of stay, mortality, primary discharge diagnosis, and primary procedure groups [21]. All data used to perform this analysis were de-identified and accessed in compliance with the Health Insurance Portability and Accountability Act. As a retrospective analysis of a de-identified database, the research was exempt from IRB review under 45 CFR 46.101(b)(4).

\section{Inclusion/exclusion criteria}

Any inpatient hospital visit in the Premier Hospital Database from January 1, 2010 through September 30, 2015 was eligible for inclusion. Inpatient was defined as a visit which included an overnight stay. Patient visits were excluded if a patient had a record of end stage renal disease requiring dialysis (ESRD ICD-9 code: 585.6), kidney transplantation (ICD-9 code: V42.0, 996.81, or 55.6x) or AKI (ICD-9 code: 584.9) upon admission (determined by a variable that indicated the patient had the condition upon admission). To isolate the risk of renal events among oncology patients hospitalized for diagnosis or treatment of cancer, visits with a secondary or historical diagnosis of cancer were excluded. Visits where the primary diagnosis or reason for the inpatient stay was cancer were included (Table 5 in Appendix).

\section{Variables of interest}

Patient visits with a record of primary cancer were further categorized by the following types of cancer: Bone, Breast, Colorectal, Endocrine, Gastrointestinal, Gynecological, Hemolymph, Leukemia, Liver, Lung, Neurological, Respiratory, Skin, Urinary and Miscellaneous (rare cancers).

The primary outcome of interest was a composite of adverse renal events, defined as one or more of the following: AKI, acute renal failure requiring dialysis, CI-AKI or renal failure (ICD-9 codes Table 6 in 
Appendix). Acute renal events were identified as being outcomes if there was a record of the event during the hospitalization and the event of interest was not recorded as present on admission.

To identify usage of CM, keyword text mining was performed on patients' charge master billing files. Using product brand names and generic keywords for CM use, the following categories were created: iodinated, non-iodinated, or unknown type. If no evidence of CM usage was found on the visit, the visit was assumed to have no $\mathrm{CM}$ usage. CM usage could have occured during a CT or CTA scan, see Table 7 of Appendix for codes used to define CT and CTA scans.

In order to quantify the effect of CKD, a dichotomous variable was made for CKD status based on the presence of CKD stage recorded in the visit. Additionally, an ordinal variable was created for CKD stage $(0=$ no disease, stage 1 , stage 2 , stage 3 , stages 4 \&5) (Table 8 in Appendix). It is important to note, that patients with unspecified CKD were only included in the dichotomous variable and excluded in the staging variable due to the non-specificity of their renal disease status.

The following variables were summarized prior to statistical modeling: patient demographics (age, race, gender, insurance type, and admission type), visit characteristics (whether or not the patient underwent a CT, CM usage and type), patient conditions (primary cancer, type of cancer, CKD severity, and overall disease severity as measured by the Elixhauser Comorbidity Index (ECI Table 9 in Appendix)) [22]. All components of the composite of renal AEs were described prior to multivariable modeling by the following key model inputs: CKD by severity, CT (with or without iodinated $\mathrm{CM}$ ) and cancer type.

\section{Statistical analyses}

All multivariable renal $\mathrm{AE}$ models adjusted for differences in both patient demographics and comorbid conditions. The hospital fixed-effects specification was used to account for time-invariant variation across a hospital that was otherwise unobservable. This methodological choice was made to compensate for the non-random relationship between patients and hospital choice which may result in variation across hospitals in both patient mix (e.g. the share and severity of oncology patients) and in the rate of renal events which may lead to a spurious correlation. By limiting the analysis to variation within hospitals, we study patients treated in a similar environment using similar standards of care and hospital protocols. The decision to utilize a particular product or drug during a hospital visit may depend on formal hospital guidelines, physician practice patterns or preferences, negotiated reimbursement schedules with insurance companies, and other local (geographic and/or hospital) characteristics.

All analysis was performed in SAS version 9.4 (Cary, NC).

\section{Results}

A total of 29,850,475 inpatient visits across 611 hospitals met the study inclusion criteria (Fig. 1). The average age of patients at the time of the inpatient visit was 45 years (standard deviation (sd) 27.5). The majority of patients were female $(60 \%)$, Caucasian (65\%), and the most frequent insurer was Medicare (34\%). Emergency and urgent hospitalizations made up $61 \%$ of all visits. Overall, $7 \%$ of inpatient visits had a record of a CT and $80 \%$ of visits had no record of CM (Table 1).

The population had a mean ECI score of 2.1 (sd 2.17), comorbid conditions and frequencies are shown in Table 2. Among the $6 \%$ of visits with CKD, the CKD stage was: stage $1(0.7 \%)$, stage $2(5.6 \%)$, stage 3 (36.5\%), stage $4 / 5(12.4 \%)$ and stage unspecified (44.8\%). Cancer was the primary diagnosis in $3.4 \%$ of visits. The highest percentage of primary cancer visits reported were: gastrointestinal (16.1\%), urinary (14.6\%) and lung $(13.1 \%)$.

The unadjusted rates of the renal $\mathrm{AE}$ outcome and its components are reported in Table 3 by the following key variables: CKD stage, CT (with or without iodinated $\mathrm{CM}$ ) and cancer type. The unadjusted baseline rate of the renal AEs was $0.5 \%$ for inpatient visits without cancer, $\mathrm{CKD}$ or $\mathrm{CT}$ and $\mathrm{CM}$. The frequency of renal events increased with CKD severity (0.9\% for patients with no record of CKD; $6.1 \%$ for a patient with CKD stage 1 to $12.7 \%$ among CKD patients stage $4 \& 5$ ). Among visits with primary cancer, the unadjusted rate of renal events was $3.0 \%$, an increase from $1.4 \%$ in visits with no cancer diagnosis. The unadjusted rate of renal events varied by cancer type: leukemia (5.3\%), liver (4.3\%), urinary $(4.1 \%)$, and colorectal (4.1\%). When considering all AEs which make up the renal $\mathrm{AE}$ composite, AKI without dialysis contributed to the composite more than other components.

The fixed effects multivariable models controlled for differences in patient demographics and comorbid conditions and decomposed the risk by the following variables: CT, iodinated CM, CKD stage and cancer type (Table 4 and Fig. 2). Estimates of absolute risk of the renal AEs are reported with confidence intervals for $\mathrm{CT}$, iodinated $\mathrm{CM}, \mathrm{CKD}$ stage and cancer (Table 4). Absolute risk of an acute renal event 


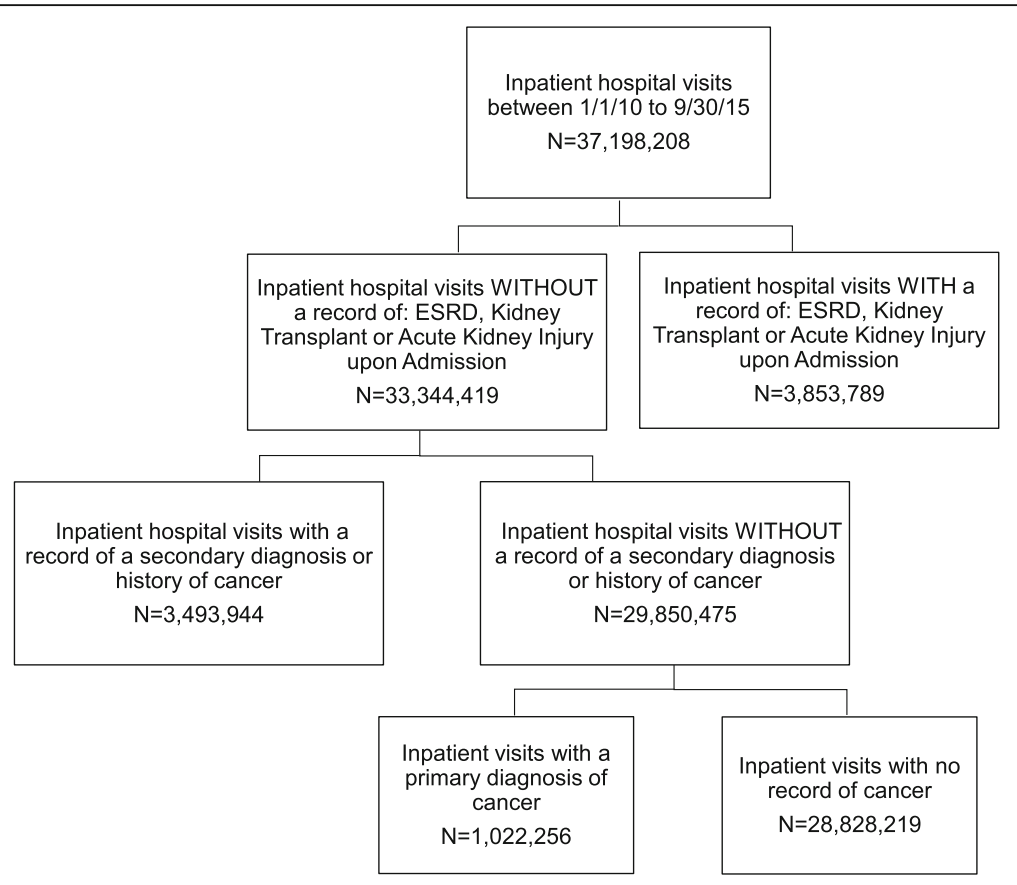

Fig. 1 Attrition Diagram

increased with non-contrast $\mathrm{CT}$ by $0.2 \%$, iodinated $\mathrm{CM}$ increased the risk by an additional $0.8 \%$. The increased risk varied by cancer type, overall, the risk of a renal event increased by $0.9 \%$. The risk by individual cancer types range from $0.3 \%$ for endocrine cancer to $2.3 \%$ for urinary cancers. Absolute risk increased with CKD severity: stage $1(2.5 \%)$, stage 2 (4.6\%), stage $3(7.2 \%)$, stage 4 \& $5(8.1 \%)$.

Figure 2 provides a cumulative visual for the regression estimates reported in Table 4. The first bar in the figure is the absolute risk of the renal AEs at baseline, $0.5 \%$. Baseline risk represents patient visits without CT, CM, CKD or cancer. From left to right, the absolute risk associated with each variable is reported as well as how the risk accumulates with each additional variable. For example, a patient hospitalized for cancer that had a CT scan with iodinated CM and CKD stage 1, had a $4.9 \%$ risk of a renal event. The absolute risk of a renal event increases substantially for patients with CKD. Inpatients who underwent a CT with iodinated CM who do not have cancer had the following risk based on CKD severity: stage $1(4.1 \%)$, stage $2(6.2 \%)$, stage $3(8.8 \%)$, stage 4 \& $5(9.7 \%)$.

\section{Discussion}

After controlling for patient demographics, comorbid conditions and hospital fixed effects, the risk of an acute renal event for hospitalized patients ranges from $0.5 \%$ at baseline (patient visits without CT, CM use, CKD or cancer experiencing $\mathrm{AKI}$ ) to as high as $10.6 \%$ (patient visits with a CT with iodinated CM with CKD stage 4 or 5 and cancer). The increasing risk with CKD stage reflects the previously reported impact of compromised renal function and adds to the literature by showing the risk of renal AEs by cancer type. The effect of a cancer diagnosis on the risk of renal AEs was $0.9 \%$, with specific cancers having up to $2.3 \%$ (for urinary cancer) added risk. The incremental risk of a renal event associated with a CT without contrast was $0.2 \%$, which clinically may be counterintuitive. This incremental risk was most likely due to the CT being a proxy for sicker patients or other procedures not controlled for in the regression analysis. Regardless of the reason, the effect is small compared to the other factors.

Large retrospective single center studies have previously explored the risk of intravenous $C M$ via propensity-matched cohort analyses [23, 24]. Such investigations differ from our current analysis in heterogeneity (or homogeneity) of population examined, this study specifically surveyed the inpatient setting while considering the impact of CKD stage and cancer diagnosis.

It is not difficult to surmise why cancer patients may be particularly susceptible to renal events given their high prevalence of renal insufficiency, concomitant nephrotoxic chemotherapeutic regimens, and predisposition to dehydration secondary to advanced age, poor 
Table 1 Patient Visit Characteristics

\begin{tabular}{|c|c|c|}
\hline & \multicolumn{2}{|l|}{ Total } \\
\hline & $\mathrm{N}$ & Percent \\
\hline Total Visits & $29,850,475$ & $100 \%$ \\
\hline \multicolumn{3}{|l|}{ Age } \\
\hline Median & 48 & \\
\hline Mean & 45.0 & \\
\hline Standard deviation & 27.50 & \\
\hline \multicolumn{3}{|l|}{ Race } \\
\hline Caucasian & $19,314,454$ & $64.7 \%$ \\
\hline African-American & $4,052,601$ & $13.6 \%$ \\
\hline Other & $6,483,420$ & $21.7 \%$ \\
\hline \multicolumn{3}{|l|}{ Gender } \\
\hline Female & $17,831,769$ & $59.7 \%$ \\
\hline Male & $12,015,263$ & $40.3 \%$ \\
\hline Unknown & 3443 & $0.0 \%$ \\
\hline \multicolumn{3}{|l|}{ Insurance } \\
\hline Commercial & $1,681,308$ & $5.6 \%$ \\
\hline Medicare & $10,010,108$ & $33.5 \%$ \\
\hline Medicaid & $6,968,569$ & $23.3 \%$ \\
\hline Managed Care & $8,043,140$ & $26.9 \%$ \\
\hline Other & $3,147,350$ & $10.5 \%$ \\
\hline \multicolumn{3}{|l|}{ Admission Type } \\
\hline Emergency & $13,780,883$ & $46.2 \%$ \\
\hline Urgent & $4,466,926$ & $15.0 \%$ \\
\hline Elective & $7,507,444$ & $25.2 \%$ \\
\hline Other/Unknown & $4,095,222$ & $13.7 \%$ \\
\hline CT Scan & $2,195,374$ & $7.4 \%$ \\
\hline \multicolumn{3}{|l|}{ Contrast Used } \\
\hline lodinated & $2,290,183$ & $7.7 \%$ \\
\hline Non-lodinated & 463,956 & $1.6 \%$ \\
\hline Both & 73,839 & $0.2 \%$ \\
\hline Unknown & $3,258,046$ & $10.9 \%$ \\
\hline None & $23,764,451$ & $79.6 \%$ \\
\hline
\end{tabular}

appetite, nausea, and vomiting [25]. It has additionally been suggested that patients with active cancer undergoing CM enhanced CT are particularly at risk of CI-AKI even in the absence of significant renal impairment as underlying renal insufficiency may be masked due to falsely low creatinine concentration resulting from diminished muscle mass [10].

This study did not explore the potential additive effects of different types of CM and chemotherapy; however, it has been suggested that CI-AKI may develop 4.5 times more frequently in cancer patients who undergo recent chemotherapy [9] and that exposure to $\mathrm{CM}$ within a week prior to nephrotoxic chemotherapeutic agents, for example cisplatin, significantly increases the risk of nephropathy [26]. Similar nephrotoxic effects of iodinated CM and chemotherapeutic agents upon the renal vasculature may rationalize the amplified risk. Not surprisingly, chemotherapy has been increasingly identified as an additional risk factor, evident by inclusion into CI-AKI consensus statements and guideline recommendations [27].

While the current analysis did not assess renal AEs by class of $\mathrm{CM}$, a recent prospective, multicenter, randomized controlled trial suggested more favorable safety profile of iso-osmolar CM (iodixanol) versus low-osmolar $\mathrm{CM}$ (iopromide) in low risk cancer patients defined by eGFR $>60 \mathrm{~mL} / \mathrm{min}$ [28]. Adequately sized and designed studies of prospective nature are warranted to elucidate findings further.

Our findings quantify absolute risk of renal events and are noteworthy given the marked consequences that AKI may elicit within the oncology setting. Salahudeen et al. recently conducted cross-sectional analysis of prospectively collected data on 3558 patients admitted to the University of Texas, M.D. Anderson Cancer Center and found higher rates of AKI versus most non-cancer settings. In patients with AKI, length of stay (100\%), cost (106\%), and odds for mortality (4.7-fold) were significantly greater [29].

On account of these implications and due to the complex bidirectional relationship between cancer and kidney function, there is need for further investigation and periprocedural recommendations. The intra-arterial administration of $\mathrm{CM}$ within interventional cardiovascular procedures has been investigated at length, with subsequent guideline development central to patient risk assessment, hydration strategies, and emphasis on limiting volumes of CM administered. While it has been suggested that overall risk is lower with intravenous administration of $\mathrm{CM}$, susceptible oncologic settings and vulnerable patients should be identified (particularly a patient's state of kidney health and timing of treatment or imaging) and integrated strategies should be employed to minimize the risk of renal events among inpatient cancer patients undergoing $\mathrm{CT}$ with $\mathrm{CM}$.

The intricate association and increasing prevalence of cancer and AKI/CKD has led to mounting interest in this complex environment and prompted evolution of the novel onco-nephrology subspecialty. Yet the relationship between cancer therapy and kidney disease remains underexplored. The burgeoning area of onco-nephrology suffers from lack of guidance for clinicians who encounter difficult and often complex problems in this complicated group of patients, and 
Table 2 Patient Comorbidities

\begin{tabular}{|c|c|c|}
\hline & \multicolumn{2}{|l|}{ Total } \\
\hline & $\mathrm{N}$ & Percent \\
\hline Total Visits & $29,850,475$ & $100 \%$ \\
\hline \multicolumn{3}{|l|}{ Elixhauser Comorbidities } \\
\hline Congestive Heart Failure & $2,956,976$ & $9.9 \%$ \\
\hline Cardiac Arrhythmia & $4,708,604$ & $15.8 \%$ \\
\hline Valvular Disease & $1,269,470$ & $4.3 \%$ \\
\hline Pulmonary Circulation Disorders & 896,999 & $3.0 \%$ \\
\hline Peripheral Vascular Disorders & $1,392,847$ & $4.7 \%$ \\
\hline Hypertension (Uncomplicated) & $10,030,305$ & $33.6 \%$ \\
\hline Hypertension (Complicated) & $1,768,162$ & $5.9 \%$ \\
\hline Paralysis & 470,505 & $1.6 \%$ \\
\hline Other Neurological Disorders & $2,076,621$ & $7.0 \%$ \\
\hline Chronic Pulmonary Disease & $5,651,859$ & $18.9 \%$ \\
\hline Diabetes (Uncomplicated) & $4,479,120$ & $15.0 \%$ \\
\hline Diabetes (Complicated) & 962,632 & $3.2 \%$ \\
\hline Hypothyroidism & $2,680,999$ & $9.0 \%$ \\
\hline Renal Failure & $1,781,578$ & $6.0 \%$ \\
\hline Liver Disease & $1,017,975$ & $3.4 \%$ \\
\hline $\begin{array}{l}\text { Peptic Ulcer Disease } \\
\text { (excluding bleeding) }\end{array}$ & 219,464 & $0.7 \%$ \\
\hline AIDS/HIV & 77,709 & $0.3 \%$ \\
\hline Lymphoma & 50,977 & $0.2 \%$ \\
\hline Metastatic Cancer & 375,880 & $1.3 \%$ \\
\hline Solid Tumor without Metastasis & 816,723 & $2.7 \%$ \\
\hline Rheumatoid Arthritis Collagen & 582,016 & $1.9 \%$ \\
\hline Coagulopathy & 988,278 & $3.3 \%$ \\
\hline Obesity & $3,335,095$ & $11.2 \%$ \\
\hline Weight Loss & 985,799 & $3.3 \%$ \\
\hline Fluid and Electrolyte Disorders & $5,086,695$ & $17.0 \%$ \\
\hline Blood Loss Anemia & 260,342 & $0.9 \%$ \\
\hline Deficiency Anemia & 711,987 & $2.4 \%$ \\
\hline Alcohol Abuse & $1,672,862$ & $5.6 \%$ \\
\hline Drug Abuse & $1,684,008$ & $5.6 \%$ \\
\hline Psychoses & 920,047 & $3.1 \%$ \\
\hline Depression & $4,026,007$ & $13.5 \%$ \\
\hline \multicolumn{3}{|l|}{ Elixhauser Comorbidity Index } \\
\hline Median & 2 & \\
\hline Mean & 2.1 & \\
\hline Std Dev & 2.17 & \\
\hline \multicolumn{3}{|l|}{ Chronic Kidney Disease } \\
\hline No CKD & $28,085,084$ & $94.0 \%$ \\
\hline CKD & $1,765,391$ & $5.9 \%$ \\
\hline
\end{tabular}

Table 2 Patient Comorbidities (Continued)

\begin{tabular}{|c|c|c|c|}
\hline & \multicolumn{2}{|l|}{ Total } & \\
\hline & $\mathrm{N}$ & Percent & \\
\hline Stage of Chronic Kidney Disease & $\mathrm{N}$ & $\%$ Overall & $\%$ of $C K D$ \\
\hline Stage 1 & 11,958 & $0.0 \%$ & $0.7 \%$ \\
\hline Stage 2 & 99,004 & $0.3 \%$ & $5.6 \%$ \\
\hline Stage 3 & 644,398 & $2.2 \%$ & $36.5 \%$ \\
\hline Stage $4 \& 5$ & 219,255 & $0.7 \%$ & $12.4 \%$ \\
\hline Unspecified & 790,776 & $2.6 \%$ & $44.8 \%$ \\
\hline \multicolumn{4}{|l|}{ Diagnosis of Cancer } \\
\hline No Cancer & $28,828,219$ & $97.0 \%$ & \\
\hline Primary Cancer & $1,022,256$ & $3.4 \%$ & \\
\hline Type of Primary Cancer & $\mathrm{N}$ & $\%$ Overall & $\%$ of Cancer \\
\hline Bone & 2991 & $0.0 \%$ & $0.3 \%$ \\
\hline Breast & 77,428 & $0.3 \%$ & $7.6 \%$ \\
\hline Colorectal & 127,275 & $0.4 \%$ & $12.5 \%$ \\
\hline Endocrine & 37,769 & $0.1 \%$ & $3.7 \%$ \\
\hline Gastrointestinal & 164,323 & $0.6 \%$ & $16.1 \%$ \\
\hline Gynecological & 64,034 & $0.2 \%$ & $6.3 \%$ \\
\hline Hemolymph & 42,572 & $0.1 \%$ & $4.2 \%$ \\
\hline Leukemia & 37,869 & $0.1 \%$ & $3.7 \%$ \\
\hline Liver & 18,022 & $0.1 \%$ & $1.8 \%$ \\
\hline Lung & 133,837 & $0.4 \%$ & $13.1 \%$ \\
\hline Miscellaneous & 120,556 & $0.4 \%$ & $11.8 \%$ \\
\hline Neurological & 29,724 & $0.1 \%$ & $2.9 \%$ \\
\hline Respiratory & 9034 & $0.0 \%$ & $0.9 \%$ \\
\hline Skin & 7073 & $0.0 \%$ & $0.7 \%$ \\
\hline Urinary & 149,749 & $0.5 \%$ & $14.6 \%$ \\
\hline
\end{tabular}

CKD Chronic Kidney Disease

development of integrated guidelines is needed [30]. The 2016 American Society of Nephrology (ASN) Onco-Nephrology Curriculum may strengthen and expand understanding of this field by underscoring risk factors of CI-AKI and suggesting preventive measures be taken in patients with GFR $<60 \mathrm{~mL} /$ min including limiting contrast volume, using iso-osmolar contrast, prehydration with normal saline, and discontinuation of concurrent nephrotoxic agents [31].

To our understanding, this is the first study to quantify absolute risk of renal events in a robust multicenter cohort of patients undergoing CM enhanced CT with decomposed analysis of contributing factors to include CM, renal function, and cancer diagnosis. Our analysis suggests that patients who receive CM are at higher risk versus those who do not. Additionally, risk is heightened with progressively advanced stages of CKD. Further, our results substantiate 
Table 3 Renal Adverse Events: Prior to Multivariable Modeling (Unadjusted)

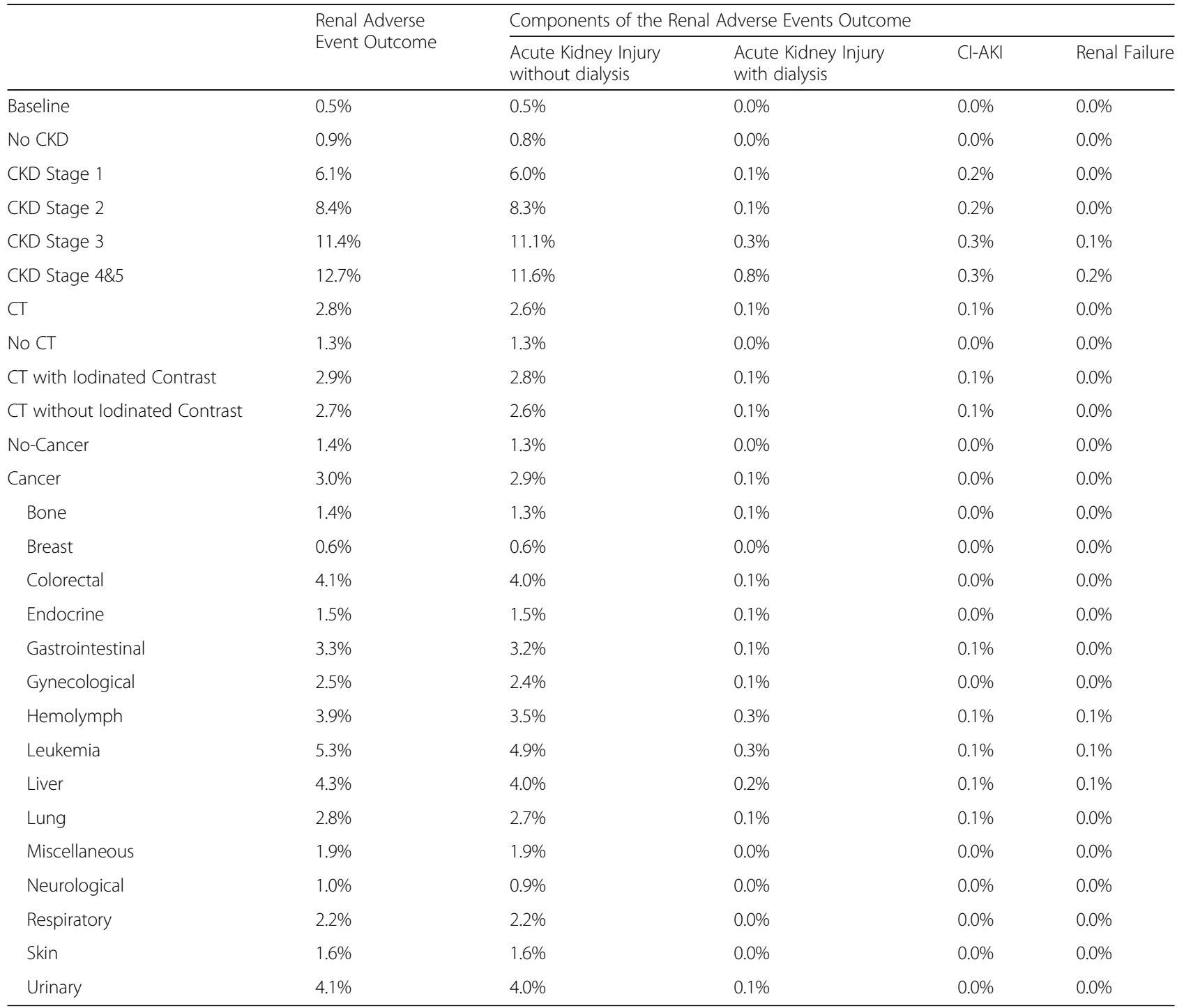

AKI Acute Kidney Injury, CKD Chronic Kidney Disease, CI-AKI Contrast induced acute kidney injury

multiple prior reports that cancer patients may be more uniquely susceptible to renal events undergoing $\mathrm{CM}$ enhanced CT versus non-cancer patients. Vulnerability of the oncologic cohort is likely multifactorial in nature and due, in part, to a high prevalence of renal insufficiency, dehydration, cachectic condition, and serial/additive renal insults induced by multiple exposures to $\mathrm{CM}$, nephrotoxic medications and chemotherapeutic regimens. Results derived from our analysis may enable significant comparison of future analyses across procedures and selected high-risk populations, ultimately driving investigative research efforts and steering quality improvement endeavors.

\section{Strengths and limitations}

Strengths of this study include the use of a comprehensive data source and use of the hospital fixed-effect specification methodology that allowed for control of time-invariant within hospital variation that is otherwise unobservable, such as physician preferences and internal protocols. The limitations of this study are those that are inherent in retrospective database analyses, which include the unit of inference (which is the visit not the patient) and potential under coding of non-billable events. The data source for this study was the Premier Healthcare Database that represents $20 \%$ of all inpatient discharges in the 
Table 4 Multivariable Estimates of Absolute risk of an Acute Renal Adverse Event

\begin{tabular}{lll}
\hline Variable & $\begin{array}{c}\text { Absolute Risk Estimate } \\
(95 \% \text { confidence interval) }\end{array}$ & $P$-Value \\
\hline CT & $0.19 \%(0.17,0.21 \%)$ & $<0.0001$ \\
lodinated CM & $0.81 \%(0.80,0.83 \%)$ & $<0.0001$ \\
CKD Stage 1 & $2.55 \%(2.35,2.74 \%)$ & $<0.0001$ \\
CKD Stage 2 & $4.64 \%(4.56,4.71 \%)$ & $<0.0001$ \\
CKD Stage 3 & $7.24 \%(7.19,7.28 \%)$ & $<0.0001$ \\
CKD Stage 4/5 & $8.14 \%(8.08,8.19 \%)$ & $<0.0001$ \\
Cancer & $0.87 \%(0.85,0.89 \%)$ & $<0.0001$ \\
Urinary & $2.33 \%(2.28,2.39 \%)$ & $<0.0001$ \\
Leukemia & $2.20 \%(2.09,2.31 \%)$ & $<0.0001$ \\
Colorectal & $1.69 \%(1.63,1.75 \%)$ & $<0.0001$ \\
Hemolymph & $1.22 \%(1.12,1.33 \%)$ & $<0.0001$ \\
Gynecological & $1.03 \%(0.95,1.11 \%)$ & $<0.0001$ \\
Liver & $1.00 \%(0.84,1.16 \%)$ & $<0.0001$ \\
Gastrointestinal & $0.59 \%(0.54,0.65 \%)$ & $<0.0001$ \\
Lung & $0.33 \%(0.27,0.39 \%)$ & $<0.0001$ \\
Endocrine & $0.29 \%(0.18,0.39 \%)$ & $<0.0001$ \\
\hline CKD Chronic Kidney Disease, CM Contrast material &
\end{tabular}

CKD Chronic Kidney Disease, CM Contrast material

US; however, given its reliance on ICD-9 Codes, there is a potential risk of coding errors. A second limitation of this data source is that it does not track patients longitudinally. Thus, it was not possible to determine if events occurred after the patient was discharged. Due to the administrative nature of the database, laboratory values ( $\mathrm{sCr}$ and GFR) were not available, we could not define $\mathrm{CI}-\mathrm{AKI}$ by $\mathrm{sCr}$, and rather, the outcome was defined by the ICD-9 code for CI-AKI which may underestimate the occurrence of this event. Finally, due to limitations of the dataset, we were unable to ascertain total volumes of $\mathrm{CM}$ administered, use of hydration strategies, or concomitant use of nephrotoxic medications or chemotherapeutic regimens.

\section{Conclusions}

This large retrospective multicenter study decomposed the risk of acute renal events among hospitalized cancer patients having $\mathrm{CT}$ either with or without iodinated $\mathrm{CM}$. The baseline risk for an acute renal event in patients without cancer or CKD and no CT or CM was $0.5 \%$. When a CT procedure was performed with iodinated $\mathrm{CM}$ the risk increased to $1.5 \%$. Patients with CKD having a CT with CM had an increased risk of an acute renal event from 2.5 to $8.1 \%$ depending on the stage of CKD. Among cancer patients, the overall risk increased from baseline by $0.9 \%$. Risk increase from baseline by type of cancer ranged from 0.3 for endocrine and lung cancer to over $2 \%$ for leukemia and urinary cancer. Therefore, cancer patients having CT with iodinated CM without CKD have a risk increase of $2.4 \%$ and when CKD is present the risk ranges from 4.9 to $10.5 \%$ depending on CKD stage. In the changing healthcare landscape, with complex inpatient admissions, understanding the underlying risks of acute renal events will be an important consideration in treatment choices for oncology patients. 


\section{Appendix}

Table 5 Cancer Coding

\begin{tabular}{|c|c|c|c|c|c|}
\hline & \\
\hline $\begin{array}{l}\text { ICD-9 Diagnosis } \\
\text { Code } 3 \text { Digit Group }\end{array}$ & $\begin{array}{l}\text { ICD-9 Diagnosis } \\
\text { Code Group Description }\end{array}$ & $\begin{array}{l}\text { Cancer } \\
\text { Category }\end{array}$ & $\begin{array}{l}\text { ICD-9 Diagnosis } \\
\text { Code } 3 \text { Digit Group }\end{array}$ & $\begin{array}{l}\text { ICD-9 Diagnosis } \\
\text { Code Group Description }\end{array}$ & $\begin{array}{l}\text { Cancer } \\
\text { Category }\end{array}$ \\
\hline 140 & MALIGNANT NEOPLASM LIP & Gastrointestinal & 188 & MALIGN NEOPL BLADDER & Urinary \\
\hline 141 & MALIG NEO TONGUE & Gastrointestinal & 189 & MAL NEO URINARY NEC/NOS & Urinary \\
\hline 142 & MAL NEO MAJOR SALIVARY & Gastrointestinal & 190 & MALIGNANT NEOPLASM EYE & Neurological \\
\hline 143 & MALIGNANT NEOPLASM GUM & Gastrointestinal & 191 & MALIGNANT NEOPLASM BRAIN & Neurological \\
\hline 144 & MALIG NEO MOUTH FLOOR & Gastrointestinal & 192 & MAL NEO NERVE NEC/NOS & Neurological \\
\hline 145 & MALIG NEO MOUTH NEC/NOS & Gastrointestinal & 193 & \multirow{2}{*}{$\begin{array}{l}\text { NEOPLASM, MALIGNANT, } \\
\text { THYROID GLAND }\end{array}$} & Endocrine \\
\hline 146 & MALIG NEO OROPHARYNX & Gastrointestinal & & & \\
\hline 147 & MALIG NEO NASOPHARYNX & Respiratory & 194 & MAL NEO OTHER ENDOCRINE & Endocrine \\
\hline 148 & MALIG NEOPL HYPOPHARYNX & Respiratory & 195 & MAL NEO OTH/ILL-DEF SITE & Miscellaneous \\
\hline 149 & OTH MALIG NEO OROPHARYNX & Gastrointestinal & 196 & MALIG NEO LYMPH NODES & Hemolymph \\
\hline 150 & MALIGNANT NEO ESOPHAGUS & Gastrointestinal & 197 & SECONDRY MAL NEO GI/RESP & Gastrointestinal \\
\hline 151 & MALIGNANT NEO STOMACH & Gastrointestinal & 198 & SEC MALIG NEO OTH SITES & Miscellaneous \\
\hline 152 & MALIG NEO SMALL BOWEL & Gastrointestinal & 199 & MALIGNANT NEOPLASM NOS & Miscellaneous \\
\hline 153 & MALIGNANT NEOPLASM COLON & Colorectal & 200 & LYMPHOSARC/RETICULOSARC & Hemolymph \\
\hline 154 & MALIG NEO RECTUM/ANUS & Colorectal & 201 & HODGKIN'S DISEASE & Hemolymph \\
\hline 155 & MALIGNANT NEOPLASM LIVER & Liver & 202 & OTH MAL NEO LYMPH/HISTIO & Hemolymph \\
\hline 156 & MAL NEO GB/EXTRAHEPATIC & Gastrointestinal & 203 & MULTIPLE MYELOMA ET AL & Leukemia \\
\hline 157 & MALIGNANT NEO PANCREAS & Gastrointestinal & 204 & LYMPHOID LEUKEMIA & Leukemia \\
\hline 158 & MALIG NEO PERITONEUM & Gastrointestinal & 205 & MYELOID LEUKEMIA & Leukemia \\
\hline 159 & OTH MALIG NEO GI/PERITON & Gastrointestinal & 206 & MONOCYTIC LEUKEMIA & Leukemia \\
\hline 160 & MAL NEO NASAL CAV/SINUS & Respiratory & 207 & OTHER SPECIFIED LEUKEMIA & Leukemia \\
\hline 161 & MALIGNANT NEO LARYNX & Respiratory & 208 & LEUKEMIA-UNSPECIF CELL & Leukemia \\
\hline 162 & MAL NEO TRACHEA/LUNG & Lung & $209.0 x-209.3 \times$ & NEUROENDOCRINE TUMORS & Endocrine \\
\hline 163 & MALIGNANT NEOPL PLEURA & Lung & 230 & CA IN SITU DIGESTIVE ORG & Gastrointestinal \\
\hline 164 & MAL NEO THYMUS/MEDIASTIN & Lung & 231 & CA IN SITU RESPIRATORY & Respiratory \\
\hline 165 & OTH/ILL-DEF MAL NEO RESP & Miscellaneous & 232 & CARCINOMA IN SITU SKIN & Skin \\
\hline 170 & MAL NEO BONE/ARTIC CART & Bone & 233 & CA IN SITU BREAST/GU & Breast \\
\hline 171 & MAL NEO SOFT TISSUE & Miscellaneous & 234 & CA IN SITU NEC/NOS & Miscellaneous \\
\hline 172 & MALIGNANT MELANOMA SKIN & Skin & 235 & UNC BEHAV NEO GI/RESP & Gastrointestinal \\
\hline 173 & OTHER MALIG NEOPL SKIN & Skin & 236 & UNC BEHAV NEO GU & Urinary \\
\hline 174 & MALIG NEO FEMALE BREAST & Breast & 237 & UNCER NEO ENDOCRINE/NERV & Endocrine \\
\hline 175 & MALIG NEO MALE BREAST & Breast & 238 & UNC BEHAV NEO NEC/NOS & Miscellaneous \\
\hline 176 & KAPOSI'S SARCOMA & Miscellaneous & 239 & UNSPECIFIED NEOPLASM & Miscellaneous \\
\hline 179 & NEOPLASM, MALIGNANT, UTERUS NEC & Gynecological & & & \\
\hline 180 & MALIG NEOPL CERVIX UTERI & Gynecological & & & \\
\hline 181 & NEOPLASM, MALIGNANT, PLACENTA & Gynecological & & & \\
\hline 182 & MALIG NEOPL UTERUS BODY & Gynecological & Table 6 Safety Ev & lents & \\
\hline 183 & MAL NEO UTERINE ADNEXA & Gynecological & Adverse Event Categ & gory & Diagnosis Code(s) \\
\hline 184 & MAL NEO FEM GEN NEC/NOS & Gynecological & Acute Kidney Injury & 58 & \\
\hline 185 & NEOPLASM, MALIGNANT, PROSTATE & Urinary & Contrast-induced & nephropathy (CIAKI) & - E947.8 \\
\hline 186 & MALIGN NEOPL TESTIS & Urinary & Acute Kidney InjuI & Iry requiring dialysis & -39.95 \\
\hline 187 & MAL NEO MALE GENITAL NEC & Urinary & Renal Failure & 586 & \\
\hline
\end{tabular}

Table 5 Cancer Coding (Continued)

Group Description MAL NEO URINARY NEC/NOS

MALIGNANT NEOPLASM EYE

Neurological

NEOPLASM, MALIGNANT,

MAL NEO OTHER ENDOCRINE

docrine

MAL NEO OTH/ILL-DEF SITE

Miscellaneous

Miscellaneous

Hemolymph

ymph

Leukemia

Leukemia

Endocrine

Respiratory

Miscellaneous

Urinary

Endocrine 
Table 7 Radiologic Imaging

\begin{tabular}{|c|c|c|c|}
\hline Code & Description & Sub-Category & Category \\
\hline \multicolumn{4}{|l|}{ ICD-9 } \\
\hline 87.03 & C.A.T. SCAN OF HEAD & $\mathrm{CT}$ - Diagnostic & $C T$ \\
\hline 87.41 & C.A.T. SCAN OF THORAX & $C T$ - Diagnostic & $C T$ \\
\hline 87.71 & C.A.T. SCAN OF KIDNEY & $\mathrm{CT}$ - Diagnostic & $C T$ \\
\hline 88.01 & C.A.T. SCAN OF ABDOMEN & $\mathrm{CT}$ - Diagnostic & $C T$ \\
\hline 88.38 & OTHER C.A.T. SCAN & $C T$ - Diagnostic & CT \\
\hline \multicolumn{4}{|l|}{ CPT } \\
\hline 70,450 & CT HEAD/BRAIN W/O DYE & $\mathrm{CT}$ - Diagnostic & $C T$ \\
\hline 70,460 & $\mathrm{CT}$ HEAD/BRAIN W/DYE & $\mathrm{CT}$ - Diagnostic & $\subset \mathrm{T}$ \\
\hline 70,470 & CT HEAD/BRAIN W/O \& W/DYE & $\mathrm{CT}$ - Diagnostic & $C T$ \\
\hline 70,480 & CT ORBIT/EAR/FOSSA W/O DYE & $C T$ - Diagnostic & $C T$ \\
\hline 70,481 & $\mathrm{CT}$ ORBIT/EAR/FOSSA W/DYE & $C T$ - Diagnostic & $C T$ \\
\hline 70,482 & CT ORBIT/EAR/FOSSA W/O\&W/DYE & $C T$ - Diagnostic & $C T$ \\
\hline 70,486 & CT MAXILLOFACIAL W/O DYE & $C T$ - Diagnostic & $C T$ \\
\hline 70,487 & CT MAXILLOFACIAL W/DYE & $C T$ - Diagnostic & $C T$ \\
\hline 70,488 & CT MAXILLOFACIAL W/O \& W/DYE & $C T$ - Diagnostic & $C T$ \\
\hline 70,490 & CT SOFT TISSUE NECK W/O DYE & $C T$ - Diagnostic & $C T$ \\
\hline 70,491 & CT SOFT TISSUE NECK W/DYE & $C T$ - Diagnostic & $C T$ \\
\hline 70,492 & CT SFT TSUE NCK W/O \& W/DYE & $C T$ - Diagnostic & $C T$ \\
\hline 70,496 & CT ANGIOGRAPHY HEAD & CT Angiography - Diagnostic & CTA \\
\hline 70,498 & CT ANGIOGRAPHY NECK & $\mathrm{CT}$ Angiography - Diagnostic & CTA \\
\hline 71,250 & CT THORAX W/O DYE & $\mathrm{CT}$ - Diagnostic & $C T$ \\
\hline 71,260 & $\mathrm{CT}$ THORAX W/DYE & $\mathrm{CT}$ - Diagnostic & $\subset T$ \\
\hline 71,270 & CT THORAX W/O \& W/DYE & $C T$ - Diagnostic & $C T$ \\
\hline 71,275 & CT ANGIOGRAPHY CHEST & CT Angiography - Diagnostic & CTA \\
\hline 72,125 & CT NECK SPINE W/O DYE & $\mathrm{CT}$ - Diagnostic & $C T$ \\
\hline 72,126 & CT NECK SPINE W/DYE & $\mathrm{CT}$ - Diagnostic & $C T$ \\
\hline 72,127 & CT NECK SPINE W/O \& W/DYE & $C T$ - Diagnostic & $C T$ \\
\hline 72,128 & CT CHEST SPINE W/O DYE & $C T$ - Diagnostic & $C T$ \\
\hline 72,129 & $\mathrm{CT}$ CHEST SPINE W/DYE & $C T$ - Diagnostic & $C T$ \\
\hline 72,130 & CT CHEST SPINE W/O \& W/DYE & $C T$ - Diagnostic & $C T$ \\
\hline 72,131 & CT LUMBAR SPINE W/O DYE & $C T$ - Diagnostic & CT \\
\hline 72,132 & CT LUMBAR SPINE W/DYE & $C T$ - Diagnostic & $C T$ \\
\hline 72,133 & CT LUMBAR SPINE W/O \& W/DYE & $C T$ - Diagnostic & $C T$ \\
\hline 72,191 & CT ANGIOGRAPH PELV W/O\&W/DYE & CT Angiography - Diagnostic & CTA \\
\hline 72,192 & CT PELVIS W/O DYE & CT - Diagnostic & $C T$ \\
\hline 72,193 & CT PELVIS W/DYE & $C T$ - Diagnostic & CT \\
\hline 72,194 & CT PELVIS W/O \& W/DYE & $\mathrm{CT}$ - Diagnostic & $C T$ \\
\hline 73,200 & CT UPPER EXTREMITY W/O DYE & $C T$ - Diagnostic & $C T$ \\
\hline 73,201 & CT UPPER EXTREMITY W/DYE & $C T$ - Diagnostic & $C T$ \\
\hline 73,202 & CT UPPR EXTREMITY W/O\&W/DYE & $\mathrm{CT}$ - Diagnostic & $C T$ \\
\hline 73,206 & CT ANGIO UPR EXTRM W/O\&W/DYE & CT Angiography - Diagnostic & CTA \\
\hline 73,700 & CT LOWER EXTREMITY W/O DYE & $\mathrm{CT}$ - Diagnostic & $C T$ \\
\hline 73,701 & CT LOWER EXTREMITY W/DYE & $C T$ - Diagnostic & $C T$ \\
\hline
\end{tabular}


Table 7 Radiologic Imaging (Continued)

\begin{tabular}{|c|c|c|c|}
\hline Code & Description & Sub-Category & Category \\
\hline 73,702 & CT LWR EXTREMITY W/O\&W/DYE & $C T$ - Diagnostic & $\mathrm{CT}$ \\
\hline 73,706 & CT ANGIO LWR EXTR W/O\&W/DYE & CT Angiography - Diagnostic & CTA \\
\hline 74,150 & CT ABDOMEN W/O DYE & $C T$ - Diagnostic & $\mathrm{CT}$ \\
\hline 74,160 & CT ABDOMEN W/DYE & $C T$ - Diagnostic & $\mathrm{CT}$ \\
\hline 74,170 & $\mathrm{CT}$ ABDOMEN W/O \& W/DYE & $\mathrm{CT}$ - Diagnostic & $\mathrm{CT}$ \\
\hline 74,175 & CT ANGIO ABDOM W/O \& W/DYE & $\mathrm{CT}$ Angiography - Diagnostic & CTA \\
\hline 74,261 & CT COLONOGRAPHY DX & $C T$ - Diagnostic & $\mathrm{CT}$ \\
\hline 74,262 & CT COLONOGRAPHY DX W/DYE & $\mathrm{CT}$ - Diagnostic & $\mathrm{CT}$ \\
\hline 74,263 & CT COLONOGRAPHY SCREENING & $\mathrm{CT}$ - Diagnostic & $\mathrm{CT}$ \\
\hline 75,571 & CT HRT W/O DYE W/CA TEST & $\mathrm{CT}$ - Diagnostic & $\mathrm{CT}$ \\
\hline 75,572 & CT HRT W/3D IMAGE & $\mathrm{CT}$ - Diagnostic & $\mathrm{CT}$ \\
\hline 75,573 & CT HRT W/3D IMAGE CONGEN & $C T$ - Diagnostic & $\mathrm{CT}$ \\
\hline 75,574 & $\mathrm{CT}$ ANGIO HRT W/3D IMAGE & CT Angiography - Diagnostic & CTA \\
\hline 75,635 & $\mathrm{CT}$ ANGIO ABDOMINAL ARTERIES & CT Angiography - Diagnostic & CTA \\
\hline 76,380 & CAT SCAN FOLLOW-UP STUDY & $C T$ - Diagnostic & $\mathrm{CT}$ \\
\hline 76,497 & CT PROCEDURE & $C T$ - Diagnostic & $\mathrm{CT}$ \\
\hline 77,011 & CT SCAN FOR LOCALIZATION & CT - Guidance & $\mathrm{CT}$ \\
\hline 77,012 & CT SCAN FOR NEEDLE BIOPSY & CT - Guidance & $\mathrm{CT}$ \\
\hline 77,013 & CT GUIDE FOR TISSUE ABLATION & CT - Guidance & $\mathrm{CT}$ \\
\hline 77,014 & CT SCAN FOR THERAPY GUIDE & CT - Guidance & $\mathrm{CT}$ \\
\hline 77,078 & CT BONE DENSITY AXIAL & $C T$ - Diagnostic & $\mathrm{CT}$ \\
\hline 77,079 & CT BONE DENSITY, PERIPHERAL & $\mathrm{CT}$ - Diagnostic & $\mathrm{CT}$ \\
\hline $0042 \mathrm{~T}$ & CT PERFUSION W/CONTRAST, CBF & $C T$ - Diagnostic & $C T \& C T A$ \\
\hline S8092 & ELECTRON BEAM COMPUTED TOMOG & $C T$ - Diagnostic & $\mathrm{CT}$ \\
\hline
\end{tabular}

Table 8 Chronic Kidney Disease

\begin{tabular}{ll}
\hline Chronic Kidney Disease Stage & ICD-9 Diagnosis Code(s) \\
\hline Chronic Kidney Disease Stage 1 & 585.1 \\
Chronic Kidney Disease Stage 2 & 585.2 \\
Chronic Kidney Disease Stage 3 & 585.3 \\
Chronic Kidney Disease Stage 4 & 585.4 \\
Chronic Kidney Disease Stage 5 & 585.5 \\
Chronic Kidney Disease, unspecified & 585.9 \\
\hline
\end{tabular}


Table 9 Elixhauser Comorbidity Index*

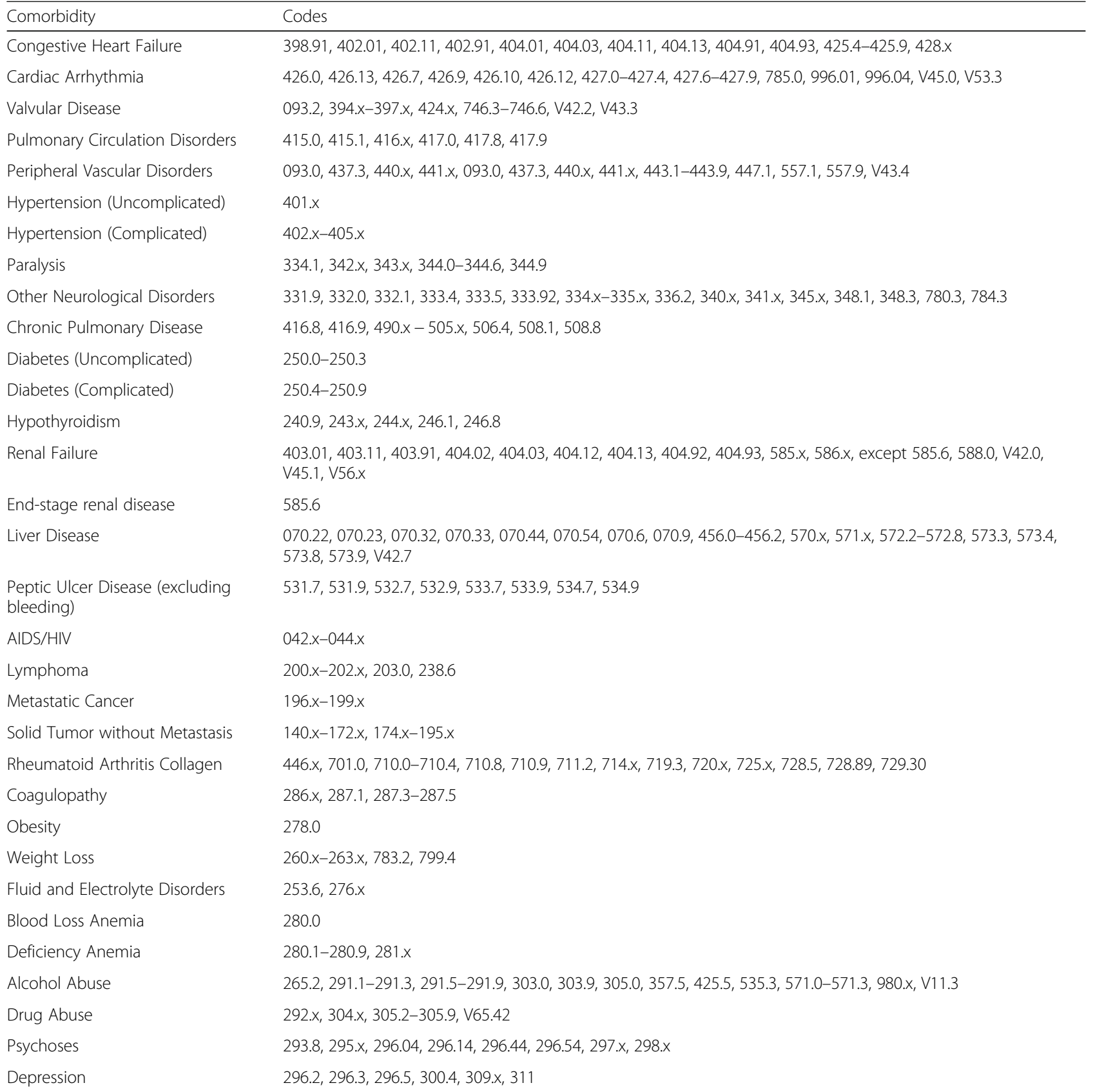

*The ECI Score includes 31 categories (Table 9 in Appendix) of comorbidities, which are associated with mortality. Each category counts as 1 point for a potential $\mathrm{ECl}$ score range of $0-31$. These comorbidities were identified using diagnosis codes that appear during the visit 


\section{Abbreviations}

AE: Adverse event(s); AKI: Acute kidney injury; ASN: American Society of Nephrology; Cl-AKI: Contrast-induced acute kidney injury; CIN: Contrast-induced nephropathy; CKD: Chronic kidney disease; CM: Contrast material; CT: Computed tomography; ECl: Elixhauser comorbidity index; ESRD: End stage renal disease; ICD-9: International classification of diseases, ninth revision; NHDS: National Hospital Discharge Survey; PC-AKI: Post-contrast acute kidney injury; SCr: Serum creatinine; US: United States

\section{Funding}

This study was funded by GE Healthcare.

\section{Availability of data and materials}

The data that support the findings of this study are available from Premier Hospital Database, but restrictions apply to the availability of these data and were used under license for the current study; therefore, they are not publicly available. The analyzable dataset is available from the authors upon reasonable request, and with permission of Premier Hospital Database.

\section{Authors' contributions}

All authors contributed to the concept and design of the study and contributed critical revision to the manuscript. MR and CG were responsible for the data analysis, MR, CG, EB were responsible for interpretation of results and drafting the manuscript. CN, SK, CG, MR, EB, and RM, approved the final version for journal submission. All authors read and approved the final manuscript.

\section{Ethics approval}

All data used to perform this analysis were de-identified and accessed in compliance with the Health Insurance Portability and Accountability Act. As a retrospective analysis of a de-identified database, the research was exempt from Institutional Review Board review under 45 Code of Federal Regulations 46.101(b)(4).

\section{Consent for publication}

Not applicable.

\section{Competing interests}

$\mathrm{CN}$ has research grant funding from and is a consultant to GE Healthcare. CG, MR, and EB are employees of CTI Clinical Trial \& Consulting Services which is a consultant to GE Healthcare. SK has research grant funding from Angiodynamics, Royalties from Springer and Elsevier, is an investor in Althea Healthcare and is a consultant to GE Healthcare and Koo Foundation (Taiwan). RM is a consultant to GE Healthcare.

\section{Publisher's Note}

Springer Nature remains neutral with regard to jurisdictional claims in published maps and institutional affiliations.

\section{Author details}

${ }^{1}$ MD Anderson Cancer Center, 1515 Holcombe Boulevard, Houston, TX 77030-4009, USA. '2University of Texas Southwestern Medical Center, 5323 Harry Hines Blvd, Dallas 75390-8834, TX, USA. ${ }^{3} \mathrm{CTI}$ Clinical Trial \& Consulting Services100 E, RiverCenter Blvd, Covington, KY 41011, USA. ${ }^{4}$ University of California San Diego 0892 UCSD Medical Center, 9500 Gilman Drive, La Jolla, CA 92037, USA.

Received: 3 April 2018 Accepted: 21 July 2018

Published online: 24 August 2018

\section{References}

1. Bottinor W, Polkampally P, Jovin I. Adverse reactions to iodinated contrast media. Int J Angiol. 2013;22:149-54.

2. Brockow K, Christiansen C, Kanny G, Clement O, Barbaud A, Bircher A, et al. Management of hypersensitivity reactions to iodinated contrast media. Allergy. 2005;60:150-8.

3. Morcos SK, Thomsen HS. Adverse reactions to iodinated contrast media. Eur Radiol. 2001;11:1267-75.

4. Mehran R, Nikolsky E. Contrast-induced nephropathy: definition, epidemiology, and patients at risk. Kidney Int Suppl. 2006;(100):S11-5.
5. Mizuno T, Sato W, Ishikawa K, Shinjo H, Miyagawa Y, Noda Y, et al. KDIGO (kidney disease: improving global outcomes) criteria could be a useful outcome predictor of cisplatin-induced acute kidney injury. Oncology. 2012;82:354-9.

6. Rawson JV, Pelletier AL. When to order a contrast-enhanced CT. Am Fam Physician. 2013;88:312-6.

7. American College of Radiology. ACR manual on contrast media Version 10.3 [https://www.acr.org/-/media/ACR/Files/Clinical-Resources/Contrast_Media. pdf] Accessed 5 Oct 2017.

8. Eng J, Wilson RF, Subramaniam RM, Zhang A, Suarez-Cuervo C, Turban S, et al. Comparative effect of contrast media type on the incidence of contrastinduced nephropathy: a systematic review and meta-analysis. Ann Intern Med. 2016;164:417-24.

9. Cicin I, Erdogan B, Gulsen E, Uzunoglu S, Sut N, Turkmen E, et al. Incidence of contrast-induced nephropathy in hospitalised patients with cancer. Eur Radiol. 2014:24:184-90.

10. Hong SI, Ahn S, Lee YS, Kim WY, Lim KS, Lee JH, et al. Contrast-induced nephropathy in patients with active cancer undergoing contrast-enhanced computed tomography. Support Care Cancer. 2016;24:1011-7.

11. Huang MK, Hsu TF, Chiu YH, Chiang SC, Kao WF, Yen DH, et al. Risk factors for acute kidney injury in the elderly undergoing contrast-enhanced computed tomography in the emergency department. J Chin Med Assoc. 2013;76:271-6.

12. Newhouse JH, Kho D, Rao QA, Starren J. Frequency of serum creatinine changes in the absence of iodinated contrast material: implications for studies of contrast nephrotoxicity. AJR Am J Roentgenol. 2008;191:376-82.

13. Farolfi A, Carretta E, Luna CD, Ragazzini A, Gentili N, Casadei C, et al. Does the time between $C T$ scan and chemotherapy increase the risk of acute adverse reactions to iodinated contrast media in cancer patients? BMC Cancer. 2014;14:792

14. Farolfi A, Della Luna C, Ragazzini A, Carretta E, Gentili N, Casadei C, et al. Taxanes as a risk factor for acute adverse reactions to iodinated contrast media in cancer patients. Oncologist. 2014;19:823-8.

15. Moos SI, van Vemde DN, Stoker J, Bipat S. Contrast induced nephropathy in patients undergoing intravenous (IV) contrast enhanced computed tomography (CECT) and the relationship with risk factors: a meta-analysis. Eur J Radiol. 2013;82:e387-99.

16. Dimopoulos MA, Kastritis E, Rosinol L, Blade J, Ludwig H. Pathogenesis and treatment of renal failure in multiple myeloma. Leukemia. 2008;22:1485-93.

17. Eleutherakis-Papaiakovou V, Bamias A, Gika D, Simeonidis A, Pouli A, Anagnostopoulos A, et al. Renal failure in multiple myeloma: incidence, correlations, and prognostic significance. Leuk Lymphoma. 2007;48:337-41.

18. Gertz MA. Current therapy of myeloma induced renal failure. Leuk Lymphoma. 2008;49:833-4

19. Pahade JK, LeBedis CA, Raptopoulos VD, Avigan DE, Yam CS, Kruskal JB, et al. Incidence of contrast-induced nephropathy in patients with multiple myeloma undergoing contrast-enhanced CT. AJR Am J Roentgenol. 2011; 196:1094-101.

20. Premier Healthcare Database: Date that Informs and Preforms. [https://earn premierinc.com/white-papers/premier-healthcare-database-whitepaper] Accessed Jul 2018

21. Ernst FR, Chen E, Lipkin C, Tayama D, Amin AN. Comparison of hospital length of stay, costs, and readmissions of alteplase versus catheter replacement among patients with occluded central venous catheters. J Hosp Med. 2014;9:490-6.

22. Elixhauser A, Steiner C, Harris DR, Coffey RM. Comorbidity measures for use with administrative data. Med Care. 1998;36:8-27.

23. Davenport MS, Khalatbari S, Cohan RH, Dillman JR, Myles JD, Ellis JH. Contrast material-induced nephrotoxicity and intravenous low-osmolality iodinated contrast material: risk stratification by using estimated glomerular filtration rate. Radiology. 2013;268:719-28.

24. McDonald RJ, McDonald JS, Carter RE, Hartman RP, Katzberg RW, Kallmes DF, et al. Intravenous contrast material exposure is not an independent risk factor for dialysis or mortality. Radiology. 2014;273:714-25.

25. Heiken JP. Contrast safety in the cancer patient: preventing contrastinduced nephropathy. Cancer Imaging. 2008;8 Spec No(A):S124-7.

26. Sendur MA, Aksoy S, Yaman S, Arik Z, Tugba Kos F, Akinci MB, et al. Administration of contrast media just before cisplatin-based chemotherapy increases cisplatin-induced nephrotoxicity. J BUON. 2013;18:274-80.

27. Owen RJ, Hiremath S, Myers A, Fraser-Hill M, Barrett BJ. Canadian Association of Radiologists consensus quidelines for the prevention of contrast-induced nephropathy: update 2012. Can Assoc Radiol J. 2014;65:96-105. 
28. Terrenato I, Sperati F, Musicco F, Pozzi AF, di Turi A, Caterino M, et al. lodixanol versus iopromide in cancer patients: evidence from a randomized clinical trial. J Cell Physiol. 2018;233(3):2572-80. Epub 2017 Sep 12.

29. Salahudeen AK, Doshi SM, Pawar T, Nowshad G, Lahoti A, Shah P. Incidence rate, clinical correlates, and outcomes of AKI in patients admitted to a comprehensive cancer center. Clin J Am Soc Nephrol. 2013;8:347-54.

30. Cosmai L, Porta C, Gallieni M, Perazella MA. Onco-nephrology: a decalogue. Nephrol Dial Transplant. 2016;31:515-9.

31. Perazella MA. Online Curricula: Onco-Nephrology [https://www.asn-online org/education/distancelearning/curricula/onco/] Accessed 10 Nov 2017.

Ready to submit your research? Choose BMC and benefit from:

- fast, convenient online submission

- thorough peer review by experienced researchers in your field

- rapid publication on acceptance

- support for research data, including large and complex data types

- gold Open Access which fosters wider collaboration and increased citations

- maximum visibility for your research: over $100 \mathrm{M}$ website views per year

At $\mathrm{BMC}$, research is always in progress.

Learn more biomedcentral.com/submissions 